Article

\title{
Effects of Ginger Extract on Laying Performance, Egg Quality, and Antioxidant Status of Laying Hens
}

\author{
Chao Wen ${ }^{1} \mathbb{C}$, Yunfeng $\mathrm{Gu}^{1}{ }^{1}$, Zhengguo Tao ${ }^{2}$, Zongjia Cheng ${ }^{2}$, Tian Wang ${ }^{1}$ and Yanmin Zhou ${ }^{1, *}$ \\ 1 College of Animal Science and Technology, Nanjing Agricultural University, Nanjing 210095, China; \\ wenage@163.com (C.W.); 13705187568@163.com (Y.G.); tianwangnjau@163.com (T.W.) \\ 2 Leader Bio-technology Co., Ltd., Guangzhou 510663, China; ttaaoo888@sina.com (Z.T.); \\ chengzongjia@leadergz.com (Z.C.) \\ * Correspondence: zhouym@njau.edu.cn; Tel.: +86-025-8439-6067
}

Received: 10 September 2019; Accepted: 19 October 2019; Published: 23 October 2019

Simple Summary: The application of in-feed antibiotic growth promoters was banned in many countries due to their negative effects, and several kinds of feed additives were widely investigated as antibiotic alternatives, in which natural plant-derived products received much attention due to their environmentally friendly properties and numerous biological activities. Ginger (Zingiber officinale Roscoe), a widely used herbal medicine and spice, was proven to have potential as an antibiotic alternative in poultry feed, but there is little literature on the efficacy of ginger extract (GE), which has concentrated bioactive compounds with high bioavailability. Our results showed that dietary GE supplementation increased egg weight, improved egg quality, and reduced the yolk cholesterol content of laying hens. Decreased serum activities of alanine transaminase and aspartate transaminase and improved antioxidant status were observed in the GE group. Our study demonstrated the potential benefits of GE in laying hens.

\begin{abstract}
The objective of this study was to investigate the effects of ginger extract (GE) as a dietary supplement for laying hens. A total of 40-week-old 288 Hyline Brown laying hens were randomly divided into two groups with six replicates, and fed a basal diet with or without $100 \mathrm{~g} / \mathrm{t}$ GE for eight weeks. Dietary GE supplementation increased egg weight, albumin height, and Haugh unit of eggs, and decreased yolk cholesterol content and activities of alanine transaminase and aspartate transaminase in serum at eight weeks. Moreover, GE resulted in higher total superoxide dismutase (T-SOD) activity and lower malondialdehyde (MDA) content in yolk at four and eight weeks and in serum. It was concluded that GE was effective in increasing egg weight and improving the egg quality and antioxidant status of laying hens.
\end{abstract}

Keywords: antioxidant status; egg quality; ginger extract; laying hen

\section{Introduction}

With the increase in concerns about environmental and food safety, the application of antibiotic growth promoters in laying hens was banned in many countries, and numerous studies were conducted to investigate the potential of many additives as antibiotic alternatives in recent years, in which natural plant-derived products received much attention due to their environmentally friendly properties and numerous biological activities [1,2]. For example, the positive effects of several plant-derived products on egg production, egg quality, and antioxidant capacity of laying hens were demonstrated in recent studies [3-5]. As one of most common natural nutraceuticals, which refer to food-derived products with potential pharmaceutical activity [6-8], ginger (Zingiber officinale Roscoe) was used worldwide as herbal medicine and spice for many years due to its medical and culinary characteristics. It is effective 
for the treatment of arthritis, fever, vomiting, migraine, hypercholesterolemia, and ulcer [9]. The most important bioactive components of ginger responsible for its pungent taste and pharmacological activities were shown to be gingerols, including 6-, 8-, 10-gingerol, etc. [10]. Gingerols are a group of phenolic compounds present as yellow oil at room temperature, and they exhibit a host of biological activities, ranging from anticancer to antioxidant, antimicrobial, anti-inflammatory, and antiallergic activities, as well as various central nervous system activities [11]. Gingerols were proven to alleviate oxidative stress of animals induced by mycotoxins, heavy metals, aging, etc. [12-14].

The potential benefits of ginger application as an antibiotic alternative in poultry production were demonstrated [15]. Several studies showed the positive effects of ginger on egg production, egg quality, and the antioxidant status of laying hens [16-18]. As ginger contains low concentrations of gingerols that are enclosed in the cell wall and not easily absorbed by animals, ginger extract (GE) with concentrated gingerols may have better bioavailability and is, thus, more convenient to be used as a feed additive. However, based on our knowledge, there was little research conducted to evaluate the efficacy of GE in laying hens. Therefore, the objective of this study was to investigate the effects of GE on laying performance, egg quality, and the antioxidant status of serum and yolk in laying hens.

\section{Materials and Methods}

\subsection{Experimental Design, Diets, and Husbandry}

All procedures were approved by Nanjing Agricultural University Institutional Animal Care and Use Committee (Certification No.: SYXK (Su)2017-0007).

The GE used in this study was provided by Leader Bio-technology Co., Ltd. (Zhuhai, Guangdong, China) and prepared as follows: briefly, fresh ginger roots were dried, ground, and extracted by subcritical butane extraction. Then, butane was removed by reduced pressure, and extracted ginger oil was coated with starch and gelatin to obtain GE in powder form. The content of total gingerols in GE was $40.3 \mathrm{~g} / \mathrm{kg}$, which was composed of $78.3 \%$ 6-gingerol, $10.2 \%$ 8-gingerol, and $11.5 \% 10$-gingerol as analyzed by high-performance liquid chromatography. Briefly, GE was dissolved in distilled water assisted by ultrasound. Then, hexane was added and mixed, followed by centrifugation at $3000 \mathrm{r} / \mathrm{min}$ for $5 \mathrm{~min}$ in order to separate the hexane phase. The amount of gingerols in hexane was quantified as previously described [19]. Gingerols were chromatographically separated by a sub-2- $\mu \mathrm{m}$ particle column. Acetonitrile-water was used as the mobile phase at a flow rate of $1.0 \mathrm{~mL} / \mathrm{min}$, and the detection wavelength was set at $280 \mathrm{~nm}$.

A total of 288 Hyline Brown laying hens (40 weeks of age) were used in this study. After two weeks of adaptation period, the hens were allocated to two groups with six replicates of 24 hens (Figure 1). A commercial corn-soybean meal diet (Table 1) with or without GE (100 g/t) was used for an eight-week study. Hens were allowed free access to mash feed and water throughout the experiment and were exposed to a a 16-h/8-h light/dark cycle. Egg production and egg weight were recorded daily and feed consumption was recorded weekly per replicate. Egg mass and feed-to-egg ratios were calculated.

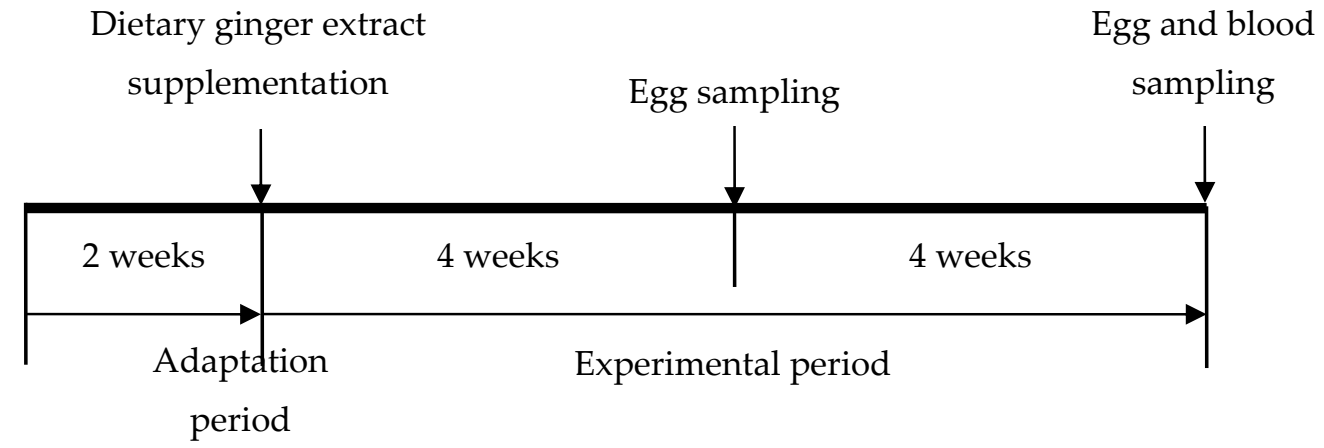

Figure 1. Scheme of experimental design. 
Table 1. Ingredient and nutrient composition of the basal diet ( $\mathrm{g} / \mathrm{kg}$ unless otherwise stated).

\begin{tabular}{cc}
\hline Items & Content \\
\hline Ingredient & \\
Corn & 620 \\
Soybean meal & 250 \\
Limestone & 100 \\
Dicalcium phosphate & 12 \\
Methionine & 1 \\
Sodium chloride & 3 \\
Premix ${ }^{1}$ & 14 \\
Nutrient composition & 10.81 \\
Metabolizable energy (MJ/kg) & 157 \\
Crude protein & 7.6 \\
Lysine & 3.6 \\
Methionine & 5.4 \\
Methionine + cystine & 41.7 \\
Calcium & 3.1 \\
Available phosphorus &
\end{tabular}

${ }^{1}$ Premix supplied per kilogram of diet: transretinyl acetate, 11,000 IU; cholecalciferol, 3500 IU; all-rac- $\alpha$-tocopherol acetate, $20 \mathrm{mg}$; menadione, $1.5 \mathrm{mg}$; thiamin, $1 \mathrm{mg}$; riboflavin, $6 \mathrm{mg}$; nicotinamide, $40 \mathrm{mg}$; choline chloride, $350 \mathrm{mg}$; calcium pantothenate, $10 \mathrm{mg}$; pyridoxine $\mathrm{HCl}, 2 \mathrm{mg}$; biotin, $0.04 \mathrm{mg}$; folic acid, $1 \mathrm{mg}$; cobalamin, $0.012 \mathrm{mg}$; Fe (ferrous sulfate), $60 \mathrm{mg}$; Cu (copper sulfate), $5 \mathrm{mg}$; Mn (manganese sulfate), $100 \mathrm{mg}$; Zn (zinc oxide), $65 \mathrm{mg}$; I (calcium iodate), $0.8 \mathrm{mg}$; Se (sodium selenite), $0.3 \mathrm{mg}$.

\subsection{Sample Collection}

At four and eight weeks of the experimental period, one egg per replicate was randomly selected for an egg quality assay, and the yolk was frozen at $-20^{\circ} \mathrm{C}$ until analysis. At eight weeks, one hen was randomly selected, and blood samples were taken from the wing vein, centrifuged at $3000 \times g$ for 15 min at $4{ }^{\circ} \mathrm{C}$ to separate the serum, which was frozen at $-20^{\circ} \mathrm{C}$ for further analysis.

\subsection{Egg Quality Assay}

Eggshell strength was measured by a compression tester (Model-II, Robotmation, Tokyo, Japan), and shell thickness was the average value of measurements at three points (blunt end, equator, and sharp end) by a micrometer. Yolk color, albumen height, and Haugh unit were analyzed by an egg multi-tester (EMT-7300, Robotmation, Tokyo, Japan). The egg yolk, albumin, and shell were weighed to calculate their percentages of egg weight.

\subsection{Yolk Fat and Cholesterol Contents}

Yolk fat content was determined by the Folch method [20]. Briefly, $0.4 \mathrm{~g}$ of yolk was homogenized with $6 \mathrm{~mL}$ of a chloroform/methanol (2/1) mixture at room temperature. Then, $2 \mathrm{~mL}$ of water was added, and the mixture was agitated and centrifuged at $2500 \mathrm{r} / \mathrm{min}$ for $10 \mathrm{~min}$. The upper phase was removed by siphoning, and the lower phase containing lipids was filtered to a pre-weighed tube. The filtrate was then evaporated under a nitrogen stream and weighed again to calculate yolk fat content. Cholesterol content was determined as previously described [21]. Briefly, $0.1 \mathrm{~g}$ of yolk was mixed thoroughly with $0.3 \mathrm{~mL}$ of $33 \%(w / v) \mathrm{KOH}$ and $3 \mathrm{~mL}$ of $95 \%$ ethanol, and then placed in a $60{ }^{\circ} \mathrm{C}$ water bath for $15 \mathrm{~min}$. After cooling, $10 \mathrm{~mL}$ of hexane and $3 \mathrm{~mL}$ of distilled water were added and mixed. Appropriate aliquots of hexane layer were pipetted into a colorimeter tube, and the solvent was evaporated under nitrogen. Then, $2 \mathrm{~mL}$ of $o$-phthalaldehyde and $1 \mathrm{~mL}$ of concentrated sulfuric acid were added and mixed, and absorbance was read at $550 \mathrm{~nm}$ using a spectrophotometer.

\subsection{Serum Transaminase Activities}

Serum alanine transaminase (ALT) and aspartate transaminase (AST) activities were determined by commercial kits (Jiancheng Bioengineering Institute, Nanjing, China).

\subsection{Antioxidant Status}

Total superoxide dismutase (T-SOD) activity and malondialdehyde (MDA) content in yolk and serum were measured to evaluate the antioxidant status of laying hens. After thawing, the yolk 
was homogenized $(1: 9, w / v)$ by ice-cold physiological saline solution (for T-SOD assay) or anhydrous ethanol (for MDA assay), and then centrifuged at $5000 \times g$ for $10 \mathrm{~min}$ at $4{ }^{\circ} \mathrm{C}$ to collect the supernatant. The T-SOD activity and MDA content in the supernatant were measured using the nitrite method [22] and thiobarbituric acid method [23], respectively, using commercial kits (Jiancheng Bioengineering Institute, Nanjing, China).

\subsection{Statistical Analysis}

All data were analyzed as a completely randomized design using one-way ANOVA (SPSS, 2008). The differences were considered to be significant at $p<0.05$. The ANOVA test with $p$-values between 0.05 and 0.10 was considered as a trend toward significance.

\section{Results}

\subsection{Laying Performance}

Compared with the control group, dietary GE supplementation increased $(p<0.05)$ egg weight and tended $(p<0.1)$ to increase egg mass (Table 2). The average daily feed intake was not affected significantly, although an increasing trend $(p<0.1)$ was also observed in GE group. There was no difference in laying rate or feed to egg ratio.

Table 2. Effects of ginger extract on performance of laying hens.

\begin{tabular}{ccccc}
\hline Item & Control & Ginger Extract & SEM $^{\mathbf{1}}$ & $p$-Value \\
\hline Laying rate $(\%)$ & 87.61 & 88.95 & 0.81 & 0.433 \\
Egg weight $(\mathrm{g})$ & 60.14 & 61.30 & 0.28 & 0.031 \\
Egg mass $(\mathrm{g})$ & 52.69 & 54.53 & 0.55 & 0.094 \\
Average daily feed intake $(\mathrm{g})$ & 111.98 & 112.69 & 0.19 & 0.053 \\
Feed-to-egg ratio & 2.13 & 2.07 & 0.02 & 0.185 \\
\hline
\end{tabular}

${ }^{1} \mathrm{SEM}$, standard errors of means $(n=6)$. Data were analyzed by one-way ANOVA.

\subsection{Egg Quality}

The laying hens fed diets supplemented with GE had higher $(p<0.05)$ albumin height and Haugh unit of eggs than the control hens at both four and eight weeks, but yolk color, eggshell strength, and eggshell thickness did not differ (Table 3). The percentages of eggshell, yolk, and albumin were similar between the groups.

Table 3. Effects of ginger extract on egg quality of laying hens.

\begin{tabular}{|c|c|c|c|c|}
\hline Item & Control & Ginger Extract & SEM $^{1}$ & $p$-Value \\
\hline \multicolumn{5}{|l|}{4 weeks } \\
\hline Eggshell strength (kg) & 3.06 & 3.49 & 0.19 & 0.270 \\
\hline Eggshell thickness ( $\mu \mathrm{m})$ & 286.50 & 297.44 & 6.81 & 0.448 \\
\hline Yolk color & 7.52 & 7.65 & 0.12 & 0.592 \\
\hline Albumin height (mm) & 6.33 & 7.70 & 0.35 & 0.044 \\
\hline Haugh unit & 76.88 & 85.37 & 2.20 & 0.048 \\
\hline Eggshell ratio (\%) & 12.27 & 13.08 & 0.31 & 0.195 \\
\hline Yolk ratio (\%) & 25.42 & 26.65 & 0.73 & 0.424 \\
\hline Albumin ratio (\%) & 62.31 & 60.26 & 0.93 & 0.289 \\
\hline \multicolumn{5}{|l|}{8 weeks } \\
\hline Eggshell strength (kg) & 4.00 & 3.90 & 0.16 & 0.756 \\
\hline Eggshell thickness $(\mu \mathrm{m})$ & 344.56 & 348.89 & 7.51 & 0.788 \\
\hline Yolk color & 7.28 & 7.18 & 0.16 & 0.764 \\
\hline Albumin height (mm) & 6.32 & 7.08 & 0.18 & 0.024 \\
\hline Haugh unit & 80.20 & 84.53 & 1.06 & 0.032 \\
\hline Eggshell ratio (\%) & 13.95 & 13.92 & 0.25 & 0.954 \\
\hline Yolk ratio (\%) & 27.24 & 26.05 & 0.51 & 0.262 \\
\hline Albumin ratio (\%) & 58.81 & 60.03 & 0.51 & 0.256 \\
\hline
\end{tabular}

${ }^{1}$ SEM, standard errors of means $(n=6)$. Data were analyzed by one-way ANOVA. 


\subsection{Yolk Fat and Cholesterol Contents}

The contents of fat and cholesterol in yolk did not differ between the groups at four weeks (Table 4). However, laying hens fed diets supplemented with GE had lower $(p<0.05)$ yolk cholesterol content than the control group at eight weeks, but yolk fat content was still not affected.

Table 4. Effects of ginger extract on yolk fat and cholesterol contents of laying hens.

\begin{tabular}{ccccc}
\hline Item & Control & Ginger Extract & SEM $^{\mathbf{1}}$ & $p$-Value \\
\hline 4 weeks & & & & \\
Fat $(\%)$ & 29.85 & 28.89 & 0.50 & 0.367 \\
Cholesterol (mg/g) & 18.66 & 18.55 & 0.21 & 0.810 \\
8 weeks & & & & \\
Fat (\%) & 31.79 & 32.41 & 0.49 & 0.553 \\
Cholesterol (mg/g) & 20.60 & 19.27 & 0.33 & 0.033 \\
\hline
\end{tabular}

${ }^{1}$ SEM, standard errors of means $(n=6)$. Data were analyzed by one-way ANOVA.

\subsection{Serum Transaminase Activities}

The activities of ALT and AST in serum were reduced $(p<0.05)$ by dietary GE supplementation compared with the control group (Table 5).

Table 5. Effects of ginger extract on serum transaminase activities of laying hens.

\begin{tabular}{ccccc}
\hline Item $^{\mathbf{1}}$ & Control & Ginger Extract & SEM $^{\mathbf{2}}$ & $\boldsymbol{p}$-Value \\
\hline ALT (U/L) & 1.81 & 1.36 & 0.11 & 0.023 \\
AST (U/L) & 17.60 & 14.83 & 0.52 & 0.002
\end{tabular}

${ }^{1}$ ALT, alanine transaminase; AST, aspartate transaminase. ${ }^{2}$ SEM, standard errors of means $(n=6)$. Data were analyzed by one-way ANOVA.

\subsection{Antioxidant Status}

Laying hens fed diets supplemented with GE had higher $(p<0.05)$ T-SOD activity and lower $(p<0.05)$ MDA content in yolk at four and eight weeks and in serum than the control hens (Table 6).

Table 6. Effects of ginger extract on antioxidant status of laying hens.

\begin{tabular}{ccccc}
\hline Item $^{\mathbf{1}}$ & Control & Ginger Extract & SEM $^{\mathbf{2}}$ & $p$-Value \\
\hline T-SOD & & & & \\
4-week yolk (U/g) & 93.52 & 121.02 & 6.70 & 0.032 \\
8-week yolk (U/g) & 90.79 & 113.40 & 4.63 & 0.006 \\
Serum (U/mL) & 296.45 & 366.24 & 11.53 & $<0.001$ \\
MDA & & & & \\
4-week yolk (U/g) & 171.66 & 161.75 & 2.54 & 0.045 \\
8-week yolk (U/g) & 169.16 & 149.95 & 4.33 & 0.017 \\
Serum (nmol/mL) & 6.51 & 5.11 & 0.32 & 0.018 \\
\hline
\end{tabular}

${ }^{1} \mathrm{~T}$-SOD, total superoxide dismutase; MDA, malondialdehyde. ${ }^{2} \mathrm{SEM}$, standard errors of means $(n=6)$. Data were analyzed by one-way ANOVA.

\section{Discussion}

This study indicated that dietary GE supplementation increased egg weight and tended to increase egg mass. There was no obvious difference in average daily feed intake, although an increasing trend was observed in the GE group, suggesting that GE might increase egg weight by increasing feed utilization but not feed intake. Our finding was similar to the results of Zhao et al. [24], who observed higher egg mass in laying hens fed diets supplemented with ginger powder. Ademola et al. [25] also reported that mixtures of ginger and garlic significantly increased the egg weight of laying hens. 
However, Yang et al. [26] reported that ginger root supplementation improved laying rate and feed conversion ratio but did not affect egg weight or egg mass. The discrepancy may be due to the physical form and dosage of ginger. In their study, diets were supplemented with $10 \mathrm{~g} / \mathrm{kg}$ ginger powder, which contained not only bioactive compounds but also other nutrients such as carbohydrates and protein [27].

Dietary GE increased albumin height and Haugh unit at both four and eight weeks, which was consistent with the results of Damaziak et al. [28], suggesting that GE might improve albumin quality. This might be attributed to the antioxidant property of gingerols in GE, which probably minimized albumen quality deterioration through lower lipid and protein oxidation [28]. However, previous research indicated that ginger root powder did not affect albumin height or Haugh unit in laying hens at 32 weeks of age [29]. The discrepancy might be due to the difference in laying hen age, which is the most important factor affecting the albumen quality of the freshly laid egg [30]. The effects of ginger might be more obvious for older hens, when albumen quality usually begins to deteriorate. There was no difference in other egg quality traits, indicating that GE did not affect yolk pigmentation, eggshell quality, or egg composition.

There was no difference in fat content of yolk at either four or eight weeks, suggesting that GE did not affect fat deposition in yolk. However, GE decreased yolk cholesterol content only at eight weeks, implying that a period of time might be needed to show the hypocholesterolemic effect of GE. Our data were in accordance with the results of Gurbuz and Salih [17], who reported that ginger root powder reduced yolk cholesterol but not fat content at eight weeks. The hypocholesterolemic effect of ginger was also observed in broilers [31], rats [32], and mice [33]. This might be due to the inhibitory effect of phenolic compounds in GE on 3-hydroxy-3-methylglutaryl coenzyme A, which plays an important role in cholesterol synthesis [16]. In addition, the decrease of yolk cholesterol content may also be attributed to the changes of high-density lipoprotein cholesterol (HDL-C) metabolism, which is involved in reverse cholesterol transport. It was reported that GE could increase serum HDL-C level in rats fed a high-fat diet [34]. Our finding implies that GE may have potential as a feed additive for producing low-cholesterol eggs, which would be preferred by customers because cholesterol is a risk marker for cardiovascular diseases, such as coronary heart disease and stroke $[35,36]$.

Activities of ALT and AST in serum are often used as indicators of liver health because the two enzymes are synthesized in liver and can be released into blood when liver injury occurs $[37,38]$. In this study, GE decreased activities of ALT and AST in serum, indicating that GE improved liver health of laying hens. Similar results were reported by Malekizadeh et al. [39], who found that 3\% ginger rhizome powder supplementation decreased serum ALT and AST activities of laying hens. Such effects of ginger were also observed in broilers [40] and laying quails [41]. The improved hepatic function may be attributed to the antioxidant compounds such as 6-gingerol in GE. Previous studies showed the protective effects of 6-gingerol against liver dysfunction induced by oxidative stress in vitro and in vivo $[12,13,42]$.

The laying hens fed GE had higher T-SOD activity and lower MDA content in yolk at four and eight weeks and in serum, suggesting that GE was effective in improving antioxidant status of laying hens and eggs, which might contribute to increased albumin height and Haugh unit as shown above. Our finding was consistent with the results of Zhao et al. [24], who observed increased T-SOD activity and decreased MDA concentration in yolk and serum of laying hens fed diets supplemented with ginger powder. Yang et al. [26] also reported that increased Haugh unit of eggs was accompanied by improved serum antioxidant status in laying hens fed ginger root. This might be explained by the radical-scavenging activity of antioxidant compounds in GE, which inhibit lipid peroxidation [43] and improve organ function as partly reflected by decreased ALT and AST activities in serum, thus enhancing the synthesis of antioxidant enzymes [14]. 


\section{Conclusions}

This study confirmed that dietary GE supplementation increased egg weight, and improved albumin height and Haugh unit of eggs, but reduced yolk cholesterol content and activities of ALT and AST in serum at eight weeks. Moreover, the antioxidant status of yolk and serum was also improved by GE. Therefore, GE may be used for the production of eggs with better quality and lower cholesterol level, which is beneficial in decreasing the risk of cardiovascular diseases in humans.

Author Contributions: Formal analysis, C.W. and Y.G.; resources, Z.T. and Z.C.; writing-original draft preparation, C.W.; writing-review and editing, T.W.; supervision, Y.Z.

Funding: This research received no external funding.

Acknowledgments: We thank Leader Bio-technology Co., Ltd. for kindly providing the GE used in this study.

Conflicts of Interest: The authors declare no conflicts of interest.

\section{References}

1. Venkitanarayanan, K.; Kollanoor-Johny, A.; Darre, M.J.; Donoghue, A.M.; Donoghue, D.J. Use of plant-derived antimicrobials for improving the safety of poultry products. Poult. Sci. 2013, 92, 493-501. [CrossRef]

2. Yang, C.; Chowdhury, M.; Huo, Y.; Gong, J. Phytogenic compounds as alternatives to in-feed antibiotics: Potentials and challenges in application. Pathogens 2015, 4, 137-156. [CrossRef] [PubMed]

3. Ahmad, A.; Abid, H.; Waheed, S.; Tarar, O.; Zahra, Y.; Tehmina, S.; Ali, T. Effects of replacing antibiotic growth promoters (AGPS) with botanical extracts and oils in feed of laying hens on production, performance and some microbial counts in feces. J. Anim. Plant Sci. 2016, 26, 893-900.

4. Alagawany, M.; Abd El-Hack, M.E.; Arain, M.; Arif, M. Effect of some phytogenic additives as dietary supplements on performance, egg quality, serum biochemical parameters and oxidative status in laying hens. Indian J. Anim. Sci. 2017, 87, 103-108.

5. Abou-Elkhair, R.; Selim, S.; Hussein, E. Effect of supplementing layer hen diet with phytogenic feed additives on laying performance, egg quality, egg lipid peroxidation and blood biochemical constituents. Anim. Nutr. 2018, 4, 394-400. [CrossRef] [PubMed]

6. Santini, A.; Novellino, E. Nutraceuticals-Shedding light on the grey area between pharmaceuticals and food. Expert Rev. Clin. Pharmacol. 2018, 11, 545-547. [CrossRef]

7. Daliu, P.; Santini, A.; Novellino, E. From pharmaceuticals to nutraceuticals: Bridging disease prevention and management. Expert Rev. Clin. Pharmacol. 2019, 12, 1-7. [CrossRef]

8. Daliu, P.; Santini, A.; Novellino, E. A decade of nutraceutical patents: Where are we now in 2018? Expert Opin. Ther. Pat. 2018, 28, 875-882. [CrossRef]

9. Ali, B.H.; Blunden, G.; Tanira, M.O.; Nemmar, A. Some phytochemical, pharmacological and toxicological properties of ginger (Zingiber officinale Roscoe): A review of recent research. Food Chem. Toxicol. 2008, 46, 409-420. [CrossRef]

10. Alsherbiny, M.A.; Abd-Elsalam, W.H.; El badawy, S.A.; Taher, E.; Fares, M.; Torres, A.; Chang, D.; Li, C.G. Ameliorative and protective effects of ginger and its main constituents against natural, chemical and radiation-induced toxicities: A comprehensive review. Food Chem. Toxicol. 2019, 123, 72-97. [CrossRef]

11. Semwal, R.B.; Semwal, D.K.; Combrinck, S.; Viljoen, A.M. Gingerols and shogaols: Important nutraceutical principles from ginger. Phytochemistry 2015, 117, 554-568. [CrossRef] [PubMed]

12. Joshi, D.; Srivastav, S.K.; Belemkar, S.; Dixit, V.A. Zingiber officinale and 6-gingerol alleviate liver and kidney dysfunctions and oxidative stress induced by mercuric chloride in male rats: A protective approach. Biomed. Pharmacother. 2017, 91, 645-655. [CrossRef] [PubMed]

13. Vipin, A.V.; Raksha Rao, K.; Kurrey, N.K.; Anu Appaiah, K.A.; Venkateswaran, G. Protective effects of phenolics rich extract of ginger against Aflatoxin $\mathrm{B}_{1}$-induced oxidative stress and hepatotoxicity. Biomed. Pharmacother. 2017, 91, 415-424.

14. Li, J.; Wang, S.; Yao, L.; Ma, P.; Chen, Z.; Han, T.-L.; Yuan, C.; Zhang, J.; Jiang, L.; Liu, L.; et al. 6-gingerol ameliorates age-related hepatic steatosis: Association with regulating lipogenesis, fatty acid oxidation, oxidative stress and mitochondrial dysfunction. Toxicol. Appl. Pharmacol. 2019, 362, 125-135. [CrossRef] [PubMed] 
15. Ogbuewu, I.P.; Mbajiorgu, C.A.; Okoli, I.C. Antioxidant activity of ginger and its effect on blood chemistry and production physiology of poultry. Comp. Clin. Pathol. 2019, 28, 655-660. [CrossRef]

16. Akbarian, A.; Golian, A.; Sheikh Ahmadi, A.; Moravej, H. Effects of ginger root (Zingiber officinale) on egg yolk cholesterol, antioxidant status and performance of laying hens. J. Appl. Anim. Res. 2011, 39, 19-21. [CrossRef]

17. Gurbuz, Y.; Salih, Y.G. Influence of sumac (Rhus Coriaria L.) and ginger (Zingiber officinale) on egg yolk fatty acid, cholesterol and blood parameters in laying hens. J. Anim. Physiol. Anim. Nutr. 2017, 101, 1316-1323. [CrossRef] [PubMed]

18. Ibtisham, F.; Nawab, A.; Niu, Y.; Wang, Z.; Wu, J.; Xiao, M.; An, L. The effect of ginger powder and Chinese herbal medicine on production performance, serum metabolites and antioxidant status of laying hens under heat-stress condition. J. Therm. Biol. 2019, 81, 20-24. [CrossRef]

19. Li, X.; Zhu, Z.-Y.; Wu, Y.-T.; Chai, Y.-F.; Zhang, G.-Q.; Lou, Z.-Y. Rapid and accurate analytical method for the determination of gingerols in three medicinal gingers (Zingiber officinale Roscoe) by high performance liquid chromatography. Anal. Lett. 2008, 41, 1732-1741. [CrossRef]

20. Folch, J.; Lees, M.; Sloane Stanley, G.H. A simple method for the isolation and purification of total lipides from animal tissues. J. Biol. Chem. 1957, 226, 497-509.

21. Rudel, L.L.; Morris, M. Determination of cholesterol using o-phthalaldehyde. J. Lipid Res. 1973, 14, $364-366$. [PubMed]

22. Ōyanagui, Y. Reevaluation of assay methods and establishment of kit for superoxide dismutase activity. Anal. Biochem. 1984, 142, 290-296. [CrossRef]

23. Placer, Z.A.; Cushman, L.L.; Johnson, B.C. Estimation of product of lipid peroxidation (malonyl dialdehyde) in biochemical systems. Anal. Biochem. 1966, 16, 359-364. [CrossRef]

24. Zhao, X.; Yang, Z.B.; Yang, W.R.; Wang, Y.; Jiang, S.Z.; Zhang, G.G. Effects of ginger root (Zingiber officinale) on laying performance and antioxidant status of laying hens and on dietary oxidation stability. Poult. Sci. 2011, 90, 1720-1727. [CrossRef] [PubMed]

25. Ademola, S.; Lawal, T.; Egbewande, O.; Farinu, G. Influence of dietary mixtures of garlic and ginger on lipid composition in serum, yolk, performance of pullet growers and laying hens. Int. J. Poult. Sci. 2012, 11, 196-201. [CrossRef]

26. Yang, C.W.; Ding, X.; Zhao, X.; Guo, Y.X.; Mu, A.L.; Yang, Z.B. Effects of star anise (Illicium verum Hook. f.), salvia miltiorrhiza (Salvia miltiorrhiza Bge) and ginger root (Zingiber officinale Roscoe) on laying performance, antioxidant status and egg quality of laying hens. Europ. Poult. Sci. 2017, 81. [CrossRef]

27. Prakash, J. Chemical composition and antioxidant properties of ginger root (Zingiber officinale). J. Med. Plants Res. 2010, 4, 2674-2679.

28. Damaziak, K.; Riedel, J.; Gozdowski, D.; Niemiec, J.; Siennicka, A.; Rog, D. Effects of ginger or ginger and thyme extract in laying hens feeding on productive results and eggs quality. Ann. Warsaw Univ. Life Sci. SGGW Anim. Sci. 2018, 57, 5-18. [CrossRef]

29. Gurbuz, Y.; Salih, Y. Effects of sumac and ginger as feed additives on the performance, egg traits and blood parameters of Atak-S laying hens. Anim. Nutr. Feed Technol. 2018, 18, 399-408. [CrossRef]

30. Williams, K.C. Some factors affecting albumen quality with particular reference to Haugh unit score. Worlds Poult. Sci. J. 1992, 48, 5-16. [CrossRef]

31. Zhang, G.F.; Yang, Z.B.; Wang, Y.; Yang, W.R.; Jiang, S.Z.; Gai, G.S. Effects of ginger root (Zingiber officinale) processed to different particle sizes on growth performance, antioxidant status, and serum metabolites of broiler chickens. Poult. Sci. 2009, 88, 2159-2166. [CrossRef] [PubMed]

32. Al-Amin, Z.M.; Thomson, M.; Al-Qattan, K.K.; Peltonen-Shalaby, R.; Ali, M. Anti-diabetic and hypolipidaemic properties of ginger (Zingiber officinale) in streptozotocin-induced diabetic rats. Br. J. Nutr. 2006, 96, 660-666. [CrossRef] [PubMed]

33. Fuhrman, B.; Rosenblat, M.; Hayek, T.; Coleman, R.; Aviram, M. Ginger extract consumption reduces plasma cholesterol, inhibits LDL oxidation and attenuates development of atherosclerosis in atherosclerotic, apolipoprotein E-deficient mice. J. Nutr. 2000, 130, 1124-1131. [CrossRef] [PubMed]

34. Oh, S.; Lee, M.-S.; Jung, S.; Kim, S.; Park, H.; Park, S.; Kim, S.-Y.; Kim, C.-T.; Jo, Y.-H.; Kim, I.-H.; et al. Ginger extract increases muscle mitochondrial biogenesis and serum HDL-cholesterol level in high-fat diet-fed rats. J. Funct. Foods 2017, 29, 193-200. [CrossRef] 
35. Naviglio, D.; Gallo, M.; Le Grottaglie, L.; Scala, C.; Ferrara, L.; Santini, A. Determination of cholesterol in Italian chicken eggs. Food Chem. 2012, 2, 701-708. [CrossRef]

36. Abdollahi, A.M.; Virtanen, H.E.K.; Voutilainen, S.; Kurl, S.; Tuomainen, T.-P.; Salonen, J.T.; Virtanen, J.K. Egg consumption, cholesterol intake, and risk of incident stroke in men: The Kuopio Ischaemic Heart Disease Risk Factor Study. Am. J. Clin. Nutr. 2019, 110, 169-176. [CrossRef]

37. Goodla, L.; Manubolu, M.; Ravilla, S.; Poondamalli, P.R. Safety evaluation of the ethanol extract of Ammannia baccifera (Lythraceae): Assessment of acute and subacute toxicity. J. Pharm. Res. 2010, 3, 2634-2637.

38. McGill, M.R. The past and present of serum aminotransferases and the future of liver injury biomarkers. EXCLI J. 2016, 15, 817-828.

39. Malekizadeh, M.; Moeini, M.; Ghazi, S. The effects of different levels of ginger (Zingiber officinale Rosc) and turmeric (Curcuma longa Linn) rhizomes powder on some blood metabolites and production performance characteristics of laying hens. J. Agric. Sci. Technol. 2012, 14, 127-134.

40. Sahoo, N.; Mishra, S.; Swain, R.; Acharya, A.; Pattnaik, S.; Sethy, K.; Sahoo, L. Effect of turmeric and ginger supplementation on immunity, antioxidant, liver enzyme activity, gut bacterial load and histopathology of broilers. Indian J. Anim. Sci. 2019, 9, 774-779.

41. Herve, T.; Raphaël, K.J.; Ferdinand, N.; Victor Herman, N.; Willy Marvel, N.M.; Cyril D'Alex, T.; Laurine Vitrice, F.T. Effects of ginger (Zingiber officinale, Roscoe) essential oil on growth and laying performances, serum metabolites, and egg yolk antioxidant and cholesterol status in laying Japanese quail. J. Vet. Med. 2019, 2019, 7857504. [CrossRef] [PubMed]

42. Abolaji, A.O.; Ojo, M.; Afolabi, T.T.; Arowoogun, M.D.; Nwawolor, D.; Farombi, E.O. Protective properties of 6-gingerol-rich fraction from Zingiber officinale (Ginger) on chlorpyrifos-induced oxidative damage and inflammation in the brain, ovary and uterus of rats. Chem. Biol. Interact. 2017, 270, 15-23. [CrossRef] [PubMed]

43. Si, W.; Chen, Y.P.; Zhang, J.; Chen, Z.-Y.; Chung, H.Y. Antioxidant activities of ginger extract and its constituents toward lipids. Food Chem. 2018, 239, 1117-1125. [CrossRef] [PubMed]

(C) 2019 by the authors. Licensee MDPI, Basel, Switzerland. This article is an open access article distributed under the terms and conditions of the Creative Commons Attribution (CC BY) license (http://creativecommons.org/licenses/by/4.0/). 